\title{
Nonlinear Active Disturbance Rejection Control of VGT-EGR System in Diesel Engines
}

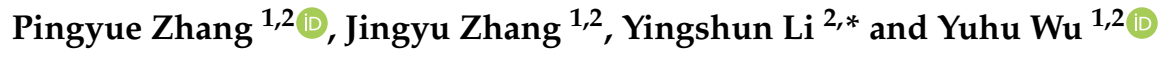 \\ 1 Key Laboratory of Intelligent Control and Optimization for Industrial Equipment of Ministry of Education, \\ Dalian University of Technology, Dalian 116024, China; zpyue@mail.dlut.edu.cn (P.Z.); \\ zjingyu@mail.dlut.edu.cn (J.Z.); wuyuhu@dlut.edu.cn (Y.W.) \\ 2 School of Control Science and Engineering, Dalian University of Technology, Dalian 116024, China \\ * Correspondence: leeys@dlut.edu.cn; Tel.: +86-158-4091-6847
}

Received: 10 September 2020; Accepted: 7 October 2020; Published: 13 October 2020

\begin{abstract}
In this paper, a nonlinear active disturbance rejection control (NLADRC) strategy based on nonlinear extended state observer (NLESO) is proposed to solve the unmodeled dynamics, coupling and disturbance due to change of working point in the variable geometry turbine (VGT) and exhaust gas recirculation (EGR) system, so as to achieve accurate control of intake manifold pressure and mass air flow in a diesel engine. To achieve decoupling, the double-input double-output (DIDO) VGT-EGR system is decomposed into two single-input single-output (SISO) subsystems, and each subsystem has a separate nonlinear active disturbance rejection controller. At the same time, the convergence proof of the designed NLESO is also given theoretically. Finally, the NLADRC controller is compared with linear active disturbance rejection controller and proportional-integral-derivative (PID) controller. Through simulation, it is indicated that the proposed NLADRC controller has better transient response performance, resistance to external disturbance and robustness to the change of engine operating point.
\end{abstract}

Keywords: nonlinear active disturbance rejection controller; variable geometry turbine; exhaust gas recirculation; diesel engine

\section{Introduction}

As one of the main power sources of trucks and ships, diesel engines have the characteristics of strong power performance, good fuel economy and long service life. However, the increasing number of diesel engines makes energy shortage more serious. In addition, the exhaust emissions of diesel engines are mainly nitrogen oxide (NOx) and particulate matter (PM), which are one of the main causes of haze formation. With the increasingly stringent emission regulations and the continuous improvement of power and economy requirements, variable geometry turbine (VGT) and exhaust gas recirculation (EGR) technology has become widely used in diesel engines. Part of the exhaust gas generated in the cylinder is delivered to the intake manifold through the EGR valve to reduce NOx emissions. However, excessive exhaust gas entering the intake manifold can cause insufficient fuel combustion. The other part of the exhaust gas through the VGT valve drives the turbine, which drives the compressor to absorb more fresh air and improve the combustion efficiency. However, excessive exhaust gas emissions will reduce the exhaust gas back to the intake manifold, thus increasing NOx emissions. In addition, complex system dynamics phenomena such as sign inversion, nonminimum phase and overshoot also exist in VGT-EGR system [1-3]. Therefore, the precise control of VGT-EGR system in diesel engines is very important to reduce emissions. At the same time, cross coupling and complex system dynamics make it difficult to control VGT-EGR system accurately. 
For the control of VGT-EGR system in diesel engines, many control strategies have been proposed by scholars. To achieve the required emission level and safe operation of the engine and turbocharger, Wahlström et al. [4] proposed a proportional-integral-derivative (PID) structure that controls the air/fuel ratio $\lambda$ and the intake manifold EGR fraction $x_{e g r}$. The air/fuel ratio $\lambda$ is controlled by the EGR valve and the EGR fraction $x_{\text {egr }}$ is controlled by the VGT position. In addition, Wahlström and Eriksson [5] proposed a control structure composed of PID controller and nonlinear compensator. Compared with the control structure without nonlinear compensator, this control structure deals with nonlinear effects and reduces EGR error. Beside PID control method, other commonly used control methods are also applied in the control of VGT-EGR system in diesel engines, such as sliding mode control [6,7], model predictive control (MPC) [8,9] and control Lyapunov function (CLF) $[10,11]$. From the perspective of system theory, Shen, Wu and Zhang applied the optimal control strategy based on multi-valued logic to the control of internal combustion (IC) engines $[12,13]$ and hybrid electric vehicles (HEVs) [14]. In addition, for some related works on optimization, and advanced control strategies for IC engines, please refer to [15-19].

However, the VGT-EGR system is a complex and uncertain system, which contains the unmodeled dynamics and the changes of different working points of the engine also have coupling effects on the system. Therefore, the control strategy of VGT-EGR system needs to be independent of the accurate model and has strong robustness to disturbance. Active disturbance rejection control (ADRC) is a method proposed by researcher Han Jingqing [20], which inherits the advantages of PID and is less dependent on the accurate model. The coupling and external disturbance of the system are regarded as the total disturbance and extended into a new state, which is observed by the extended state observer. Then, the system is transformed into an integral series control system by compensating the disturbance into the control input. In addition, to solve the contradiction between speediness and overshoot, a tracking differentiator is designed. Finally, a more efficient nonlinear state error feedback control law is used to replace the traditional PID control law. Therefore, ADRC plays an increasingly important role in the control of nonlinear system and multi-input multi-output (MIMO) system such as quadrotor [21,22], aero engine [23], and diesel engines [24-26]. In addition, Wang et al. [27] introduced the ADRC method into the control of the differential drive assist steering system of electric vehicles, and selected the standard working conditions for simulation and experimental verification. The results showed that compared with the PID controller, the ADRC controller can not only reduce the steering effort of the driver obviously, but also have better control performance in tracking accuracy and smooth road feeling of the driver. Shi et al. [28] proposed a hybrid ADRC control for the control of superheated steam temperature in coal-fired power plants. Numerical simulation results showed that the hybrid ADRC can improve the performance of tracking and disturbance rejection under the condition of good robustness. At the same time, experiments were carried out on a $150 \mathrm{MW}$ power plant simulator. The experimental results showed that the hybrid ADRC can improve the control performance of superheated steam temperature and its structure is simpler than cascade control. Zhou et al. [29] proposed the ADRC technology as a speed loop controller for permanent magnet synchronous motor. The ADRC is used to measure and compensate unknown disturbances such as rotational inertia and stator resistance, so that the system has strong against the system parameter change and external disturbance, and the decoupling control of permanent magnet synchronous motor is realized. Simulation and experimental results show that the controller has strong robustness, stability and accurate dynamic tracking performance.

However, the ADRC was originally proposed by Han in a nonlinear form, but nonlinear active disturbance rejection control (NLADRC) requires too many parameters to be adjusted. Gao proposed a bandwidth-based parameter tuning method for the first time, which simplified the ADRC from the original nonlinear form to the linear form, which greatly reduced the parameters of the controller and greatly promoted the application of ADRC. However, linear active disturbance rejection control (LADRC) cannot meet the requirements of the system which needs high control precision and fast response speed. In the decoupled control of diesel engines, Song and Xie et al. [24,25] decoupled the 
double-input double-output (DIDO) system into two independent single-input single-output (SISO) systems, each of which can be designed as an ideal monolithic object for control. The nonlinear, uncertain and time-varying process dynamics and the external disturbance are uniformly treated as a total disturbance, which is estimated and compensated by extended state observer (ESO) and eliminated in the control input, thus achieving the purpose of controlling the intake manifold pressure and air quality flow rate of diesel engines by LADRC controller. Based on the above work, our goal is to design a control strategy for diesel engines with satisfactory transient response performance, strong resistance to external disturbances and robust performance for engine operating conditions.

The contributions made in the paper can be summarized as follows.

1. Based on the work of Song and Xie $[24,25]$ on the LADRC controller in diesel engines, we designed the NLADRC controller for VGT-EGR system in order to improve the control accuracy.

2. Based on the theoretical result of Guo [30] on ADRC, we give the convergence proof of the designed NLESO, which theoretically ensures the rationality of the designed controller.

3. In addition, the NLADRC controller designed by us is compared with PID controller [24] and LADRC controller. First, the NLADRC controller we designed can quickly track the given signal without overshoot. Secondly, the control effect of the controller is not affected by the external square wave and sinusoidal control disturbance. Finally, the controller can track the given signal well after changing the diesel engine speed and fuel injection without resetting the parameters of the controller.

The rest of this paper is organized as follows: The next section describes the dynamics of diesel engines. Combined with the dynamics of Section 2, the nonlinear extended state observer is designed for intake manifold pressure and air mass flow in Section 3. Section 4 gives the convergence proof of the designed NLSEO. Section 5 presents the design of NLADRC controller and the comparative simulation results of NLADRC controller, LADRC controller and PID controller. Finally, the conclusion is given in the last section.

\section{System Dynamics}

Figure 1 shows the diesel engine model, which is mainly composed of seven parts: cylinder, compressor, turbine, intake manifold, exhaust manifold, VGT valve and EGR valve.

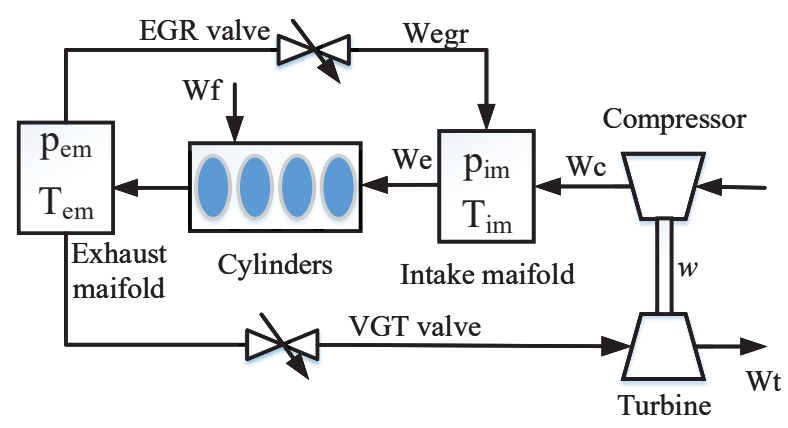

Figure 1. A model structure of the diesel engine.

According to the law of ideal gas and the law of conservation of mass, the dynamics of manifold pressure can be modeled [1] as

$$
\begin{gathered}
\dot{p}_{i m}=\frac{R T_{i m}}{V_{i m}}\left(W_{c}+W_{e g r}-W_{e}\right), \\
\dot{p}_{e m}=\frac{R T_{e m}}{V_{e m}}\left(W_{e}+W_{f}-W_{e g r}-W_{t}\right),
\end{gathered}
$$

where $p_{i m}, T_{i m}$ and $V_{i m}$ respectively represent the intake manifold pressure, temperature and volume. In addition, $p_{e m}, T_{e m}$ and $V_{e m}$ respectively represent the exhaust manifold pressure, temperature and 
volume. $W_{c}, W_{e}, W_{f}, W_{\text {egr }}$ and $W_{t}$ represent the mass air flow, the total mass flow from the intake manifold into the cylinder, the fuel mass flow into the cylinders, the mass flow through the EGR valve, and the turbine mass flow, respectively.

The fuel mass flow $W_{f}$ into the cylinder can be expressed [1] as

$$
W_{f}=\frac{10^{-6}}{120} u_{\delta} n_{e} n_{c y l}
$$

where $u_{\delta}$ represents the injected fuel, $n_{e}$ represents the engine speed and $n_{c y l}$ is the number of cylinders.

The mass flow through the EGR valve $W_{\text {egr }}$ and the turbine mass flow $W_{t}$ are expressed [25] as

$$
\begin{gathered}
W_{e g r}=A_{e g r}\left(u_{e g r}\right) \frac{\sqrt{2 p_{i m}\left(p_{e m}-p_{i m}\right)}}{\sqrt{R T_{e m}}}, \\
W_{t}=A_{v g t}\left(u_{v g t}\right) \frac{\sqrt{2 p_{a m b}\left(p_{e m}-p_{a m b}\right)}}{\sqrt{R T_{e m}}},
\end{gathered}
$$

where $u_{e g r}$ and $u_{v g t}$ are input signals for diesel engines and represent the open ratio of VGT and EGR valve, respectively. It is $0 \%$ when the valves are closed and $100 \%$ when the valves are fully open. $A_{\text {egr }}\left(u_{\text {egr }}\right)$ is a polynomial function of $u_{\text {egr }}$, so is $A_{v g t}\left(u_{v g t}\right)$.

The compressor power $P_{c}$ and turbine power $P_{t}$ can be calculated [25] as

$$
\begin{aligned}
& P_{c}=\frac{W_{c} c_{p} T_{a m b}}{\eta_{c}}\left(\left(\frac{p_{i m}}{p_{a m b}}\right)^{\mu}-1\right), \\
& P_{t}=W_{t} c_{p} T_{e m} \eta_{t}\left(1-\left(\frac{p_{a m b}}{p_{e m}}\right)^{\mu}\right),
\end{aligned}
$$

where $T_{a m b}$ and $p_{a m b}$ represent ambient temperature and pressure. $\eta_{m}, \eta_{c}$ and $\eta_{t}$ represent the mechanical efficiency in the turbocharger, the isentropic efficiency of compressor and the isentropic efficiency of turbine, respectively. $c_{p}$ is the constant pressure specific heat capacity, and $\tau_{t}$ is time constant. The power $\mu$ can be expressed as $\mu=1-\frac{1}{\gamma}$ by the specific heat capacity ratio $\gamma$.

The relationship between compressor power $P_{c}$ and turbine power $P_{t}$ can be expressed as

$$
\dot{P}_{c}=\frac{1}{\tau_{t}}\left(-P_{c}+\eta_{m} P_{t}\right)
$$

The dynamic process of the exhaust process is very fast, so it is considered a stable process, then $\dot{p}_{e m}$ is 0 , Equation (2) can be simplified [25] as

$$
W_{e}+W_{f}-W_{e g r}-W_{t}=0 .
$$

Define $g\left(u_{v g t}\right)=A_{\text {vgt }}\left(u_{v g t}\right)$ and $f\left(u_{\text {egr }}\right)=A_{\text {egr }}\left(u_{\text {egr }}\right)$, and their Taylor series at VGT valve opening $u_{v g t}=u_{0}$ and EGR valve opening $u_{\text {egr }}=u_{1}$ are

$$
\begin{aligned}
& g\left(u_{v g t}\right)=g\left(u_{0}\right)+g^{\prime}\left(u_{0}\right)\left(u_{v g t}-u_{0}\right)+\ldots+\frac{g^{n}\left(u_{0}\right)}{n !}\left(u_{v g t}-u_{0}\right)^{n}+R_{n}\left(u_{v g t}\right), \\
& f\left(u_{\text {egr }}\right)=f\left(u_{1}\right)+f^{\prime}\left(u_{1}\right)\left(u_{\text {egr }}-u_{1}\right)+\ldots+\frac{f^{n}\left(u_{1}\right)}{n !}\left(u_{\text {egr }}-u_{1}\right)^{n}+R_{n}\left(u_{\text {egr }}\right),
\end{aligned}
$$

where $R_{n}\left(u_{v g t}\right)=o\left(\left(u_{v g t}-u_{0}\right)^{n}\right), R_{n}\left(u_{\text {egr }}\right)=o\left(\left(u_{\text {egr }}-u_{1}\right)^{n}\right)$, and they represent polynomials of higher order than $n$. 
Substituting Equations (4), (8) and (9) into Equation (1), the dynamics of intake manifold pressure $p_{\text {im }}$ becomes

$$
\dot{p}_{i m}=\frac{R T_{i m}}{V_{i m}}\left(W_{c}+W_{f}\right)+K_{0} K_{1}+K_{0} g^{\prime}\left(u_{0}\right) u_{v g t},
$$

where

$$
\begin{aligned}
& K_{0}=-\frac{\sqrt{2 R} T_{i m}}{\sqrt{T_{e m}} V_{i m}} \sqrt{p_{a m b}\left(p_{e m}-p_{a m b}\right)}, \\
& K_{1}=g\left(u_{0}\right)-g^{\prime}\left(u_{0}\right) u_{0}+\ldots+\frac{g^{n}\left(u_{0}\right)}{n !}\left(u_{v g t}-u_{0}\right)^{n}+R_{n}\left(u_{v g t}\right) .
\end{aligned}
$$

Differentiate Equation (6) and convert the form, the representation of $\dot{W}_{c}$ can be expressed as

$$
\dot{W}_{c}=\frac{\dot{P}_{c}-\frac{W_{c} c_{p} T_{a m b} \mu}{\eta_{c} p_{a m b}}\left(\frac{p_{i m}}{p_{a m b}}\right)^{\mu-1} \dot{p}_{i m}}{\frac{c_{p} T_{a m b}}{\eta_{c}}\left(\left(\frac{p_{i m}}{p_{a m b}}\right)^{\mu}-1\right)} .
$$

Substituting Equations (3), (5)-(8) and (10) into Equation (12), we obtain the dynamics of mass air flow $W_{c}$ as

$$
\dot{W}_{c}=K_{2}\left(W_{e}+W_{f}\right)-K_{4} W_{c}-K_{2} K_{3} K_{5}-K_{2} K_{3} f^{\prime}\left(u_{1}\right) u_{e g r}
$$

where

$$
\begin{aligned}
\Pi_{1} & =\frac{p_{i m}}{p_{a m b}}, \Pi_{2}=\frac{p_{a m b}}{p_{e m}}, K_{2}=\frac{\eta_{m} \eta_{c} \eta_{t} \mathrm{~T}_{\mathrm{em}}\left(1-\Pi_{2}{ }^{\mu}\right)}{T_{a m b} \tau_{t}\left(\Pi_{1}^{\mu}-1\right)}, \\
K_{3} & =\frac{\sqrt{2 p_{i m}\left(p_{e m}-p_{i m}\right)}}{\sqrt{R T_{e m}}}, K_{4}=\frac{1}{\tau_{t}}+\frac{\mu \Pi_{1}{ }^{\mu-1} \dot{p}_{i m}}{p_{a m b}\left(\Pi_{1}^{\mu}-1\right)} \\
K_{5} & =f\left(u_{1}\right)-f^{\prime}\left(u_{1}\right) u_{1}+\ldots+\frac{f^{n}\left(u_{1}\right)}{n !}\left(u_{e g r}-u_{1}\right)^{n}+R_{n}\left(u_{e g r}\right) .
\end{aligned}
$$

\section{NLESO Design}

In this part, we will design the NLESO for VGT-EGR system according to the dynamics in Section 2. The decoupling control scheme is shown in Figure 2. As shown in the figure, the DIDO VGT-EGR system with $u_{v g t}$ and $u_{\text {egr }}$ as inputs and intake manifold pressure $p_{i m}$ and mass air flow $W_{c}$ as outputs is decomposed into two subsystems. One of the SISO systems takes $u_{v g t}$ as input and intake manifold pressure $p_{i m}$ as output, while the other takes $u_{\text {egr }}$ as input and mass air flow $W_{c}$ as output.

Figure 3 presents the block diagram of NLADRC controller designed for $p_{i m}$ loop of VGT-EGR system in diesel engines. NLADRC controller mainly consists of three parts: tracking differentiator (TD), nonlinear states error feedback control laws (NLSEF) and NLESO. The desired output signal $p_{i m-d}$ is arranged by TD, and then the transient process signal $p_{i m-v 1}$ is obtained. $p_{i m-v 1}$ subtracts the state signal $z_{1}$ observed by NLESO, and its deviation is used as the input of NLSEF to produce control action $u_{0}$. Then $u_{0}$ subtracts the total disturbance $z_{2}$ estimated by NLSEO and divides it by the compensation coefficient $b$ to obtain the control output $u_{\text {nladrc }}$ of NLADRC controller. Considering that the output signal of the controller may be affected by the external disturbance, the output $u_{\text {nladrc }}$ of the controller plus the external disturbance $d$ is the input signal $u_{v g t}$ of the diesel engine. 


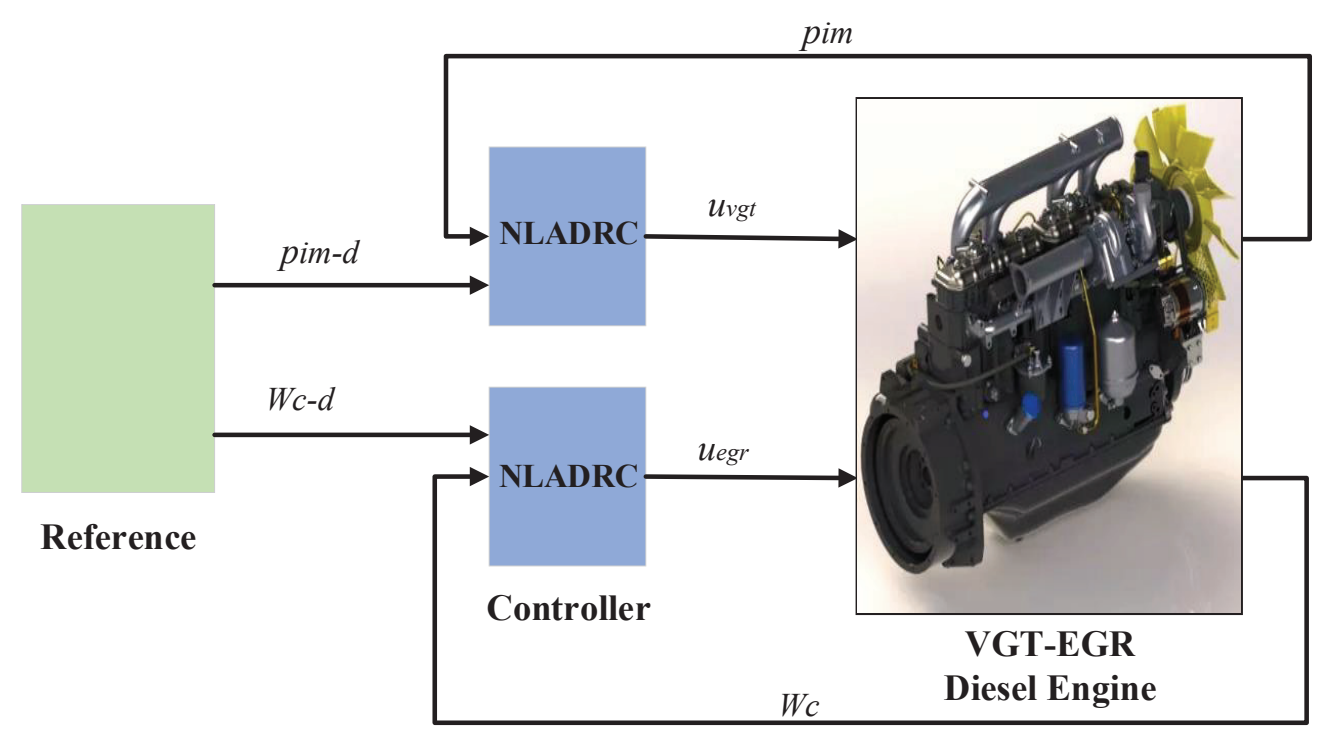

Figure 2. NLADRC controller diagram.

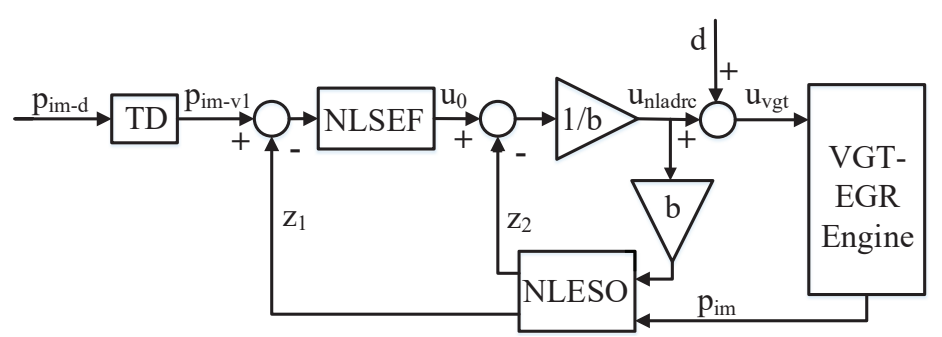

Figure 3. The structure of NLADRC controller for $p_{i m}$ loop in VGT-EGR diesel engines.

Considering that the system may be affected by external interference, we add external interference $w$ to the system (11). In addition, the system (11) is converted to the total disturbance and input form as follows

$$
\begin{aligned}
\dot{p}_{i m} & =\frac{R T_{i m}}{V_{i m}}\left(W_{c}+W_{f}\right)+K_{0} K_{1}+K_{0 g^{\prime}}\left(u_{0}\right) u_{v g t}+w \\
& =\frac{R T_{i m}}{V_{i m}}\left(W_{c}+W_{f}\right)+K_{0} K_{1}+\left(K_{0 g^{\prime}}\left(u_{0}\right)-b_{v g t}\right) u_{v g t}+b_{v g t} u_{v g t}+w \\
& =f_{p_{i m}}+w+b_{v g t} u_{v g t}=F_{p_{i m}}+b_{v g t} u_{v g t},
\end{aligned}
$$

where $F_{p_{i m}}$ represents the total disturbance of $p_{i m}$ loop. The system function $f_{p_{i m}}$ contains coupling and disturbance caused by the change of working point. The coefficient $b_{v g t}$ is an approximate estimate of $K_{0} g^{\prime}\left(u_{0}\right)$, and the estimated deviation $K_{0} g^{\prime}\left(u_{0}\right)-b_{v g t}$ between $b_{v g t}$ and $K_{0} g^{\prime}\left(u_{0}\right)$ is also included in $f_{p_{i m}}$, which is timely estimated and compensated. For the diesel engine physical system, we can notice that there are some positive constants $c_{0}, c_{1}, c_{2}$ and the positive integer $k$ that satisfy $\left|b_{\text {vgt }} u_{v g t}\right|+\left|f_{p_{i m}}\right|+|\dot{w}|+\left|\frac{\partial f_{p_{i m}}}{\partial t}\right|+\left|\frac{\partial f_{p_{i m}}}{\partial p_{i m}}\right| \leq c_{0}+c_{1}\left|p_{i m}\right|^{k}$ and $|w|+\left|p_{i m}\right| \leq c_{2}$.

Let the state variable $x_{1}(t)=p_{\text {im }}(t), x_{2}(t)=F_{p_{i m}}(t)=f_{\text {pim }}\left(t, x_{1}(t)\right)+w(t)$. Then, system (14) is expressed in the form of extended state space

$$
\left[\begin{array}{c}
\dot{x}_{1}(t) \\
\dot{x}_{2}(t)
\end{array}\right]=\left[\begin{array}{ll}
0 & 1 \\
0 & 0
\end{array}\right]\left[\begin{array}{l}
x_{1}(t) \\
x_{2}(t)
\end{array}\right]+\left[\begin{array}{c}
b_{v g t} \\
0
\end{array}\right] u_{v g t}(t)+\left[\begin{array}{l}
0 \\
1
\end{array}\right] \dot{F}_{p_{i m}}(t)
$$

According to system (15), the NLESO for the intake manifold pressure $p_{i m}$ is designed as

$$
\left\{\begin{array}{l}
\dot{z}_{1}(t)=z_{2}(t)+b_{\text {vgt }} u_{\text {vgt }}(t)+g_{1}\left(\frac{x_{1}(t)-z_{1}(t)}{\varepsilon}\right), \\
\dot{z}_{2}(t)=\frac{1}{\varepsilon} g_{2}\left(\frac{x_{1}(t)-z_{1}(t)}{\varepsilon}\right),
\end{array}\right.
$$


where $z_{1}(t)$ and $z_{2}(t)$ are estimates of the intake manifold pressure and the total disturbance, respectively. $\varepsilon$ is constant gain. $g_{1}\left(\frac{x_{1}(t)-z_{1}(t)}{\varepsilon}\right)$ and $g_{2}\left(\frac{x_{1}(t)-z_{1}(t)}{\varepsilon}\right)$ are functions of the state deviation expressed as $g_{1}\left(\frac{x_{1}(t)-z_{1}(t)}{\varepsilon}\right)=a_{1}\left(\frac{x_{1}(t)-z_{1}(t)}{\varepsilon}\right)+f a l\left(\frac{x_{1}(t)-z_{1}(t)}{\varepsilon}, 0.5,1\right)$, and $g_{2}\left(\frac{x_{1}(t)-z_{1}(t)}{\varepsilon}\right)=$ $a_{2}\left(\frac{x_{1}(t)-z_{1}(t)}{\varepsilon}\right)$. Parameters $a_{1}$ and $a_{2}$ are positive, and nonlinear function $f a l(e, \alpha, \delta)$ is specifically expressed as

$$
f a l(e, \alpha, \delta)=\left\{\begin{array}{l}
|e|^{\alpha} \operatorname{sign}(e),|e|>\delta, \\
\frac{e}{\delta^{1-\alpha}},|e| \leq \delta,
\end{array}\right.
$$

where $\alpha$ and $\delta$ are the parameters to be adjusted, and $\delta$ represents the width of the linear region.

Similar to the simplification process of Equation (11), Equation (13) can be simplified in the form of input $u_{e g r}$ and disturbance similar to (14)

$$
\dot{W}_{c}=f_{W_{c}}+w+b_{e g r} u_{e g r}
$$

according to the similar design method of $p_{i m}$ loop, NLESO can be designed for mass air flow $W_{c}$.

\section{Convergence Analysis of NLESO for the Intake Manifold Pressure}

In the above section, we designed NLESO using the intake manifold pressure $p_{i m}$ loop as an example. In this section, we will provide the convergence analysis of the proposed NLESO.

Theorem 1. The proposed NLESO given in (16) for the intake manifold pressure loop dynamics (15) have the following two properties:

1. For every positive constant $a, \lim _{\varepsilon \rightarrow 0}\left|x_{i}(t)-z_{i}(t)\right|=0$ uniformly in $t \in[a, \infty)$.

2. $\varlimsup_{t \rightarrow \infty}\left|x_{i}(t)-z_{i}(t)\right| \leq O\left(\varepsilon^{3-i}\right), i=1,2$,

where $\varlimsup_{t \rightarrow \infty}\left|x_{i}(t)-z_{i}(t)\right|=\lim _{t \rightarrow \infty} \sup \left|x_{i}(t)-z_{i}(t)\right|$, it means that the upper limit is the upper bound of the limit of the series of convergents. The state variables $x_{1}(t)$ and $x_{2}(t)$ respectively represent the intake manifold pressure $p_{i m}$ and the total disturbance $F_{p_{i m}}$. In addition, the states of observer $z_{1}(t)$ and $z_{2}(t)$ are approximations of $x_{1}(t)$ and $x_{2}(t)$, respectively.

Proof of Theorem 1. Set

$$
e_{i}(t)=x_{i}(t)-z_{i}(t), \eta_{i}(t)=\frac{e_{i}(\varepsilon t)}{\varepsilon^{2-i}}, i=1,2 .
$$

Then the derivative of $\eta_{1}(t)$ can be calculated as

$$
\begin{aligned}
\dot{\eta}_{1}(t) & =\dot{e}_{1}(\varepsilon t)=\dot{x}_{1}(\varepsilon t)-\dot{z}_{1}(\varepsilon t) \\
& =x_{2}(\varepsilon t)+b_{\text {vgt }} u_{v g t}(\varepsilon t) \\
& -z_{2}(\varepsilon t)-b_{v g t} u_{v g t}(\varepsilon t)-g_{1}\left(\frac{x_{1}(\varepsilon t)-z_{1}(\varepsilon t)}{\varepsilon}\right) \\
& =x_{2}(\varepsilon t)-z_{2}(\varepsilon t)-g_{1}\left(\eta_{1}(t)\right) \\
& =\eta_{2}(t)-g_{1}\left(\eta_{1}(t)\right) .
\end{aligned}
$$

Similarly, the derivative of $\eta_{2}(t)$ can be expressed as

$$
\begin{aligned}
\dot{\eta}_{2}(t) & =\varepsilon \dot{e}_{2}(\varepsilon t)=\varepsilon\left(\dot{x}_{2}(\varepsilon t)-\dot{z}_{2}(\varepsilon t)\right) \\
& =\varepsilon\left(\dot{F}_{p_{i m}}(\varepsilon t)-\frac{1}{\varepsilon} g_{2}\left(\frac{x_{1}(\varepsilon t)-z_{1}(\varepsilon t)}{\varepsilon}\right)\right) \\
& =-g_{2}\left(\eta_{1}(t)\right)+\varepsilon \dot{F}_{p_{i m}}(\varepsilon t) .
\end{aligned}
$$


We construct positive definite function as

$$
V(\eta(t))=\eta(t)^{T} P \eta(t)+\int_{0}^{\eta_{1}(t)} f a l(s, 0.5,1) d s
$$

where

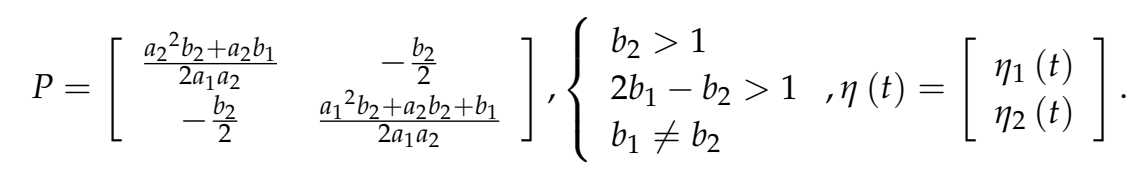

The derivative of $V(\eta(t))$ with respect to $t$ along the $\eta(t)$ can be calculated as

$$
\begin{aligned}
\frac{d}{d t} V(\eta(t)) & =\frac{\partial V}{\partial \eta_{1}(t)} \dot{\eta}_{1}(t)+\frac{\partial V}{\partial \eta_{2}(t)} \dot{\eta}_{2}(t) \\
& =\frac{\partial V}{\partial \eta_{1}(t)}\left(\eta_{2}(t)-g_{1}\left(\eta_{1}(t)\right)\right)-\frac{\partial V}{\partial \eta_{2}(t)} g_{2}\left(\eta_{1}(t)\right)+\frac{\partial V}{\partial \eta_{2}(t)} \varepsilon \dot{F}_{p_{i m}}(\varepsilon t)
\end{aligned}
$$

Next, we will calculate $\dot{F}_{p_{i m}}(\varepsilon t), \frac{\partial V}{\partial \eta_{1}(t)}\left(\eta_{2}(t)-g_{1}\left(\eta_{1}(t)\right)\right)-\frac{\partial V}{\partial \eta_{2}(t)} g_{2}\left(\eta_{1}(t)\right)$, and $\frac{\partial V}{\partial \eta_{2}(t)}$ respectively. First, we have

$$
\begin{aligned}
\dot{F}_{p_{i m}}(\varepsilon t) & =\left.\frac{d}{d s} f\left(s, x_{1}(s)\right)\right|_{s=\varepsilon t}+\dot{w}(\varepsilon t) \\
& =\varepsilon \frac{\partial}{\partial t} f\left(\varepsilon t, x_{1}(\varepsilon t)\right)+\frac{\partial}{\partial x_{1}} f\left(\varepsilon t, x_{1}(\varepsilon t)\right)\left(x_{2}(\varepsilon t)+b_{v g t} u_{v g t}(t)\right)+\dot{w}(\varepsilon t),
\end{aligned}
$$

there exists a constant $M>0$ that satisfies $M \geq\left|\dot{F}_{p_{i m}}(\varepsilon t)\right|$.

Notice that $g_{1}\left(\eta_{1}(t)\right)=a_{1} \eta_{1}(t)+f a l\left(\eta_{1}(t), 0.5,1\right)$ and $g_{2}\left(\eta_{1}(t)\right)=a_{2} \eta_{1}(t)$. Then, we have the following calculation

$$
\begin{aligned}
& \frac{\partial V}{\partial \eta_{1}(t)}\left(\eta_{2}(t)-g_{1}\left(\eta_{1}(t)\right)\right)-\frac{\partial V}{\partial \eta_{2}(t)} g_{2}\left(\eta_{1}(t)\right) \\
= & \left(\frac{a_{2}^{2} b_{2}+a_{2} b_{1}}{a_{1} a_{2}} \eta_{1}(t)-b_{2} \eta_{2}(t)+f a l\left(\eta_{1}(t), 0.5,1\right)\right)\left(\eta_{2}(t)-a_{1} \eta_{1}(t)-f a l\left(\eta_{1}(t), 0.5,1\right)\right) \\
& -\left(\frac{a_{1}^{2} b_{2}+a_{2} b_{2}+b_{1}}{2 a_{1} a_{2}} \eta_{2}(t)-b_{2} \eta_{1}(t)\right) a_{2} \eta_{1}(t) \\
= & -b_{1} \eta_{1}(t)^{2}-b_{2} \eta_{2}(t)^{2}+\left(\eta_{2}(t)-a_{1} \eta_{1}(t)\right) f a l\left(\eta_{1}(t), 0.5,1\right) \\
& -\left(\frac{a_{2}^{2} b_{2}+a_{2} b_{1}}{a_{1} a_{2}} \eta_{1}(t)-b_{2} \eta_{2}(t)+f a l\left(\eta_{1}(t), 0.5,1\right)\right) f a l\left(\eta_{1}(t), 0.5,1\right) \\
= & -b_{1} \eta_{1}(t)^{2}-b_{2} \eta_{2}(t)^{2}+\left(1+b_{2}\right) \eta_{2}(t) f a l\left(\eta_{1}(t), 0.5,1\right) \\
& -f a l\left(\eta_{1}(t), 0.5,1\right)^{2}-\left(a_{1}+\frac{a_{2}^{2} b_{2}+a_{2} b_{1}}{a_{1} a_{2}}\right) \eta_{1}(t) f a l\left(\eta_{1}(t), 0.5,1\right) \\
\leq & -b_{1} \eta_{1}(t)^{2}-b_{2} \eta_{2}(t)^{2}+\left(1+b_{2}\right) \eta_{2}(t) f a l\left(\eta_{1}(t), 0.5,1\right) \\
\leq & -b_{1} \eta_{1}(t)^{2}-b_{2} \eta_{2}(t)^{2}+\frac{1+b_{2}}{2}\left(\eta_{2}(t)^{2}+f a l\left(\eta_{1}(t), 0.5,1\right)^{2}\right)
\end{aligned}
$$


Due to $\mid$ fal $\left(\eta_{1}(t), 0.5,1\right)|\leq| \eta_{1}(t) \mid$, we can further calculate as

$$
\begin{aligned}
& \frac{\partial V}{\partial \eta_{1}(t)}\left(\eta_{2}(t)-g_{1}\left(\eta_{1}(t)\right)\right)-\frac{\partial V}{\partial \eta_{2}(t)} g_{2}\left(\eta_{1}(t)\right) \\
& \leq-b_{1} \eta_{1}(t)^{2}-b_{2} \eta_{2}(t)^{2}+\frac{1+b_{2}}{2}\left(\eta_{2}(t)^{2}+f a l\left(\eta_{1}(t), 0.5,1\right)^{2}\right) \\
& \leq-b_{1} \eta_{1}(t)^{2}-b_{2} \eta_{2}(t)^{2}+\frac{1+b_{2}}{2}\left(\eta_{2}(t)^{2}+\eta_{1}(t)^{2}\right) \\
& =-\left(\frac{2 b_{1}-b_{2}-1}{2} \eta_{1}(t)^{2}+\frac{b_{2}-1}{2} \eta_{2}(t)^{2}\right)=\eta(t)^{T} P_{1} \eta(t) \triangleq-W(\eta(t)),
\end{aligned}
$$

where

$$
P_{1}=\left[\begin{array}{cc}
\frac{2 b_{1}-b_{2}-1}{2} & 0 \\
0 & \frac{b_{2}-1}{2}
\end{array}\right] .
$$

Obviously, $V(\eta(t))$ satisfies

$$
\begin{aligned}
V(\eta(t)) & =\eta(t)^{T} P \eta(t)+\int_{0}^{\eta_{1}(t)} \text { fal }(s, 0.5,1) d s \\
& \geq \eta(t)^{T} P \eta(t) \triangleq V_{1}(\eta(t)) .
\end{aligned}
$$

We notice that $P$ is a symmetric positive definite matrix, which means that $P$ has two positive eigen values denoted by $\lambda_{1 \min }$ and $\lambda_{2 \max }$. In addition, set $\beta_{1}=\lambda_{1 \mathrm{~min}}$, we have

$$
V(\eta(t)) \geq V_{1}(\eta(t)) \geq \beta_{1}\|\eta(t)\|^{2} .
$$

Let us calculate $V(\eta(t))$ as

$$
\begin{aligned}
V(\eta(t)) & =\eta(t)^{T} P \eta(t)+\int_{0}^{\eta_{1}(t)} f a l(s, 0.5,1) d s \\
& \leq \eta(t)^{T} P \eta(t)+\int_{0}^{\eta_{1}(t)} s d s \\
& =\eta(t)^{T} P \eta(t)+\frac{\eta_{1}(t)^{2}}{2} \\
& =\eta(t)^{T} P_{2} \eta(t) \triangleq V_{2}(\eta(t)),
\end{aligned}
$$

where

$$
P_{2}=\left[\begin{array}{cc}
\frac{a_{2}{ }^{2} b_{2}+a_{2} b_{1}}{2 a_{1} a_{2}}+\frac{1}{2} & -\frac{b_{2}}{2} \\
-\frac{b_{2}}{2} & \frac{a_{1}{ }^{2} b_{2}+a_{2} b_{2}+b_{1}}{2 a_{1} a_{2}}
\end{array}\right] .
$$

Similarly, we can get the eigenvalues of symmetric positive definite matrix $P_{2}$ are $\lambda_{3 \text { min }}$ and $\lambda_{4 \max }$, respectively. In addition, set $\beta_{2}=\lambda_{4 \max }$, we have

$$
V(\eta(t)) \leq V_{2}(\eta(t)) \leq \beta_{2}\|\eta(t)\|^{2} .
$$

And for the positive definite function $W(\eta(t))$, we also have the expression as

$$
\beta_{3}\|\eta(t)\|^{2} \leq W(\eta(t)) \leq \beta_{4}\|\eta(t)\|^{2},
$$

where $\beta_{3}$ is the minimum eigenvalue of symmetric positive definite matrix $P_{1}$, and $\beta_{4}$ is the maximum eigenvalue of symmetric positive definite matrix $P_{1}$. 
We have an expression of $\frac{\partial V}{\partial \eta_{2}(t)}$ as

$$
\frac{\partial V}{\partial \eta_{2}(t)}=\frac{a_{1}^{2} b_{2}+a_{2} b_{2}+b_{1}}{2 a_{1} a_{2}} \eta_{2}(t)-b_{2} \eta_{1}(t)=\frac{\partial V_{1}}{\partial \eta_{2}(t)}
$$

so we can get

$$
\left|\frac{\partial V}{\partial \eta_{2}(t)}\right|=\left|\frac{\partial V_{1}}{\partial \eta_{2}(t)}\right| \leq\left\|\frac{\partial V_{1}}{\partial \eta(t)}\right\|=\|2 P \eta(t)\| \leq 2\|P\|\|\eta(t)\|=2 \sqrt{\lambda_{\max }\left(P^{T} P\right)}\|\eta(t)\| .
$$

Because $P$ is a symmetric positive definite matrix, we have

$$
2 \sqrt{\lambda_{\max }\left(P^{T} P\right)}\|\eta(t)\|=2 \lambda_{\max }(P)\|\eta(t)\|,
$$

and set $\beta=2 \lambda_{\max }(P)=2 \lambda_{2 \max }$, we can know that $\left|\frac{\partial V}{\partial \eta_{2}(t)}\right|$ satisfies

$$
\left|\frac{\partial V}{\partial \eta_{2}(t)}\right| \leq \beta\|\eta(t)\|
$$

So, Equation (20) combined with Equations (21) and (23)-(27), we have

$$
\begin{aligned}
\frac{d}{d t} V(\eta(t)) & =\frac{\partial V}{\partial \eta_{1}(t)}\left(\eta_{2}(t)-g_{1}\left(\eta_{1}(t)\right)\right)-\frac{\partial V}{\partial \eta_{2}(t)} g_{2}\left(\eta_{1}(t)\right)+\frac{\partial V}{\partial \eta_{2}(t)} \varepsilon \dot{F}_{p_{i m}}(\varepsilon t) \\
& \leq-W(\eta(t))+\varepsilon M \beta\|\eta(t)\| \\
& \leq-\frac{\beta_{3}}{\beta_{2}} V(\eta(t))+\frac{\sqrt{\beta_{1}}}{\beta_{1}} \varepsilon M \beta \sqrt{V(\eta(t))} .
\end{aligned}
$$

Because

$$
\frac{d}{d t} \sqrt{V(\eta(t))}=\frac{d \sqrt{V(\eta(t))}}{d V(\eta(t))} \frac{d}{d t} V(\eta(t))=\frac{1}{2 \sqrt{V(\eta(t))}} \frac{d}{d t} V(\eta(t))
$$

from Equation (28) we can get

$$
\frac{d}{d t} \sqrt{V(\eta(t))} \leq-\frac{\beta_{3}}{2 \beta_{2}} \sqrt{V(\eta(t))}+\frac{\sqrt{\beta_{1}} \varepsilon M \beta}{2 \beta_{1}}
$$

Combining Equation (24) with Equation (29), we know that $\|\eta(t)\|$ satisfies

$$
\|\eta(t)\| \leq \sqrt{\frac{V(\eta(t))}{\beta_{1}}} \leq \frac{\sqrt{\beta_{1} V(\eta(0))}}{\beta_{1}} e^{-\frac{\beta_{3}}{2 \beta_{2}} t}+\frac{\varepsilon M \beta}{2 \beta_{1}} \int_{0}^{t} e^{-\frac{\beta_{3}}{2 \beta_{2}}(t-\tau)} d \tau,
$$

which together with Equation (18) satisfies

$$
\begin{aligned}
\left|e_{i}(t)\right| & =\varepsilon^{2-i}\left|\eta_{i}\left(\begin{array}{c}
t \\
\varepsilon
\end{array}\right)\right| \leq \varepsilon^{2-i}\left\|\eta\left(\begin{array}{c}
t \\
\varepsilon
\end{array}\right)\right\| \\
& \leq \varepsilon^{2-i}\left[\frac{\sqrt{\beta_{1} V(\eta(0))}}{\beta_{1}} e^{-\frac{\beta_{3} t}{2 \beta_{2} \varepsilon}}+\frac{\varepsilon M \beta}{2 \beta_{1}} \int_{0}^{\frac{t}{\varepsilon}} e^{\frac{-\beta_{3}}{2 \beta_{2}}(t / \varepsilon-\tau)} d \tau\right] \\
& \rightarrow 0, i=1,2
\end{aligned}
$$

uniformly in $t \in[a, \infty)$ as $\varepsilon \rightarrow 0$. 


\section{NLADRC Controller Design and Simulation Results}

In this part, we will design the discrete NLADRC controller for VGT-EGR system and give the simulation results. Due to the discrete controller adopted in the subsequent simulation, we discretize (16), and then discrete NLESO for the intake manifold pressure $p_{i m}$ is expressed as

$$
\left\{\begin{array}{l}
z_{1}(k+1)=z_{1}(k)+h\left(z_{2}(k)+b_{v g t} u_{v g t}(k)+g_{1}\left(\frac{x_{1}(k)-z_{1}(k)}{\varepsilon}\right)\right), \\
z_{2}(k+1)=z_{2}(k)+h\left(\frac{1}{\varepsilon} g_{2}\left(\frac{x_{1}(k)-z_{1}(k)}{\varepsilon}\right)\right),
\end{array}\right.
$$

where $h$ is the sampling time.

The discrete form of TD is expressed [20] as

$$
\left\{\begin{array}{l}
v_{1}(k+1)=v_{1}(k)+h v_{2}(k), \\
v_{2}(k+1)=v 2(k)+h \text { fhan }\left(v_{1}(k)-v(k), v_{2}(k), r, h\right),
\end{array}\right.
$$

where $r$ is the parameter indicating the speed of the transition process, $v(k)$ is the desired intake manifold pressure, $v_{1}(k)$ is the transition process of the desired intake manifold pressure, $v_{2}(k)$ is the derivative of the transition process, and fhan $\left(x_{1}, x_{2}, r, h\right)$ is the synthesis function of the fastest control expressed [20] as

$$
\left\{\begin{array}{l}
d=r h \\
d_{0}=h d \\
y=x_{1}+h x_{2} \\
a_{0}=\sqrt{d^{2}+8 r|y|} \\
a=\left\{\begin{array}{l}
x_{2}+\frac{\left(a_{0}-d\right)}{y} \operatorname{sign}(y),|y|>d_{0} \\
x_{2}+\frac{y}{h},|y| \leq d_{0}
\end{array}\right. \\
\text { fhan }=\left\{\begin{array}{l}
-r \operatorname{sign}(a),|a|>d \\
-r \frac{a}{d},|a| \leq d
\end{array}\right.
\end{array}\right.
$$

The NLSEF is designed as

$$
\left\{\begin{array}{l}
e(k)=v_{1}(k)-z_{1}(k) \\
u(k)=k_{p} f a l(e(k), 3 / 4,0.01) .
\end{array}\right.
$$

where $k_{p}$ is the proportional gain.

The control effect after compensation by disturbance estimate $z_{2}(k)$ is as follows

$$
u_{v g t}=\frac{\left(u(k)-z_{2}(k)\right)}{b_{v g t}} .
$$

Similar to the controller design method of $p_{i m}$ loop, we can also design NLADRC controller for $W_{c}$. Therefore, we do not need to introduce the controller design process of $W_{c}$ loop in detail.

Next, we will verify the control effect of the NLADRC controller for VGT-EGR system from the transient response performance, disturbance resistance performance and robustness on the diesel engine model created by Wahlström [1], and compare it with the LADRC controller and the PID controller. And the parameters adjustment of PID controller are described by Ziegler-Nichols method in [24]. In the simulation experiment, the diesel engine working point: engine speed $n_{e}: 1900 \mathrm{r} / \mathrm{min}$, fuel injection $u_{\delta}$ step from $110 \mathrm{mg} /$ cycle to $160 \mathrm{mg} /$ cycle. The parameters of LADRC controller and NLADRC controller are summarized in Tables 1-3. 
Table 1. NLADRC controller parameters.

\begin{tabular}{ccccccc}
\hline Index & $\boldsymbol{h}$ & $\boldsymbol{b}$ & $\boldsymbol{a}_{\mathbf{1}}$ & $\boldsymbol{a}_{\mathbf{2}}$ & $\boldsymbol{\varepsilon}$ & $\boldsymbol{k} \boldsymbol{p}$ \\
\hline VGT loop & 0.01 & -454 & 3 & 1 & 0.3 & 30 \\
EGR loop & 0.01 & -0.015 & 3 & 1 & 0.4 & 20 \\
\hline
\end{tabular}

Table 2. LADRC controller parameters.

\begin{tabular}{cccccc}
\hline Index & $\boldsymbol{h}$ & $\boldsymbol{b}$ & $\boldsymbol{\beta}_{\mathbf{1}}$ & $\boldsymbol{\beta}_{\mathbf{2}}$ & $\boldsymbol{k} \boldsymbol{p}$ \\
\hline VGT loop & 0.01 & -100000 & 130 & 4225 & 1.3 \\
EGR loop & 0.01 & -0.015 & 30 & 225 & 2.2 \\
\hline
\end{tabular}

Table 3. Nonlinear function $f a l(e, \alpha, \delta)$ parameters.

\begin{tabular}{ccccc}
\hline Index & $\alpha_{v g t}$ & $\delta_{v g t}$ & $\alpha_{\text {egr }}$ & $\delta_{\text {egr }}$ \\
\hline NLESO & 0.5 & 1 & 0.5 & 1 \\
NLSEF & 0.75 & 0.01 & 0.75 & 0.01 \\
\hline
\end{tabular}

\subsection{Transient Performance}

Figure 4 and 5 present the tracking response curves of intake manifold pressure $p_{i m}$ and mass air flow $W_{c}$ to square wave signal. In the figure, the black curve represents the expected intake manifold pressure, the red curve represents the response curve with NLADRC controller, the blue curve represents the response curve with LADRC controller, and the green curve represents the response curve with PID controller, and other figures in this paper are similar. Table 4 summarizes the setting time and overshoot of the response curves of NLADRC controller, LADRC controller and PID controller.

Table 4. Setting time and overshoot of three controllers.

\begin{tabular}{cccc}
\hline Index & NLADRC & LADRC & PID \\
\hline$T_{s}$ of $p_{i m}$ loop & $6 \mathrm{~s}$ & $12 \mathrm{~s}$ & $20 \mathrm{~s}$ \\
$T_{s}$ of $W_{c}$ loop & $6 \mathrm{~s}$ & $15 \mathrm{~s}$ & $20 \mathrm{~s}$ \\
$\sigma$ of $p_{i m}$ loop & $0 \%$ & $1.5 \%$ & $3.3 \%$ \\
$\sigma$ of $W_{c}$ loop & $0 \%$ & $1.5 \%$ & $1.1 \%$ \\
\hline
\end{tabular}

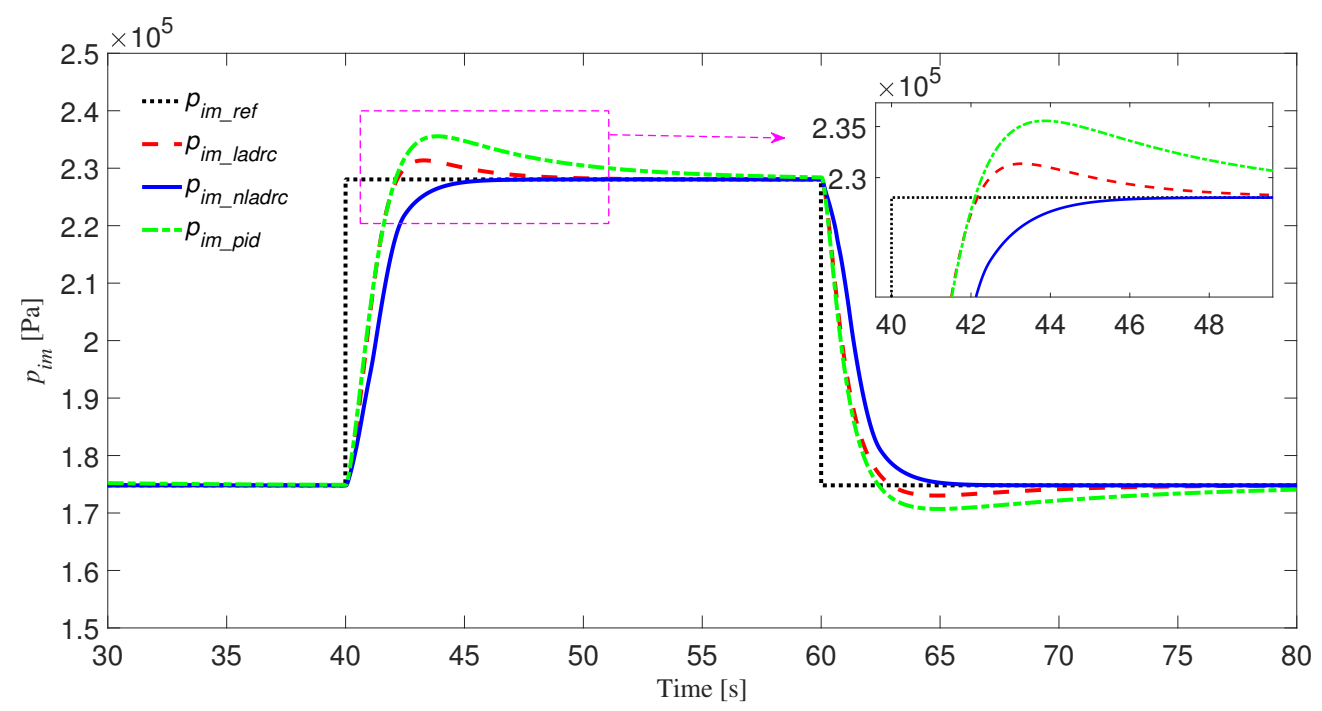

Figure 4. Response curve of intake manifold pressure $p_{i m}$. 


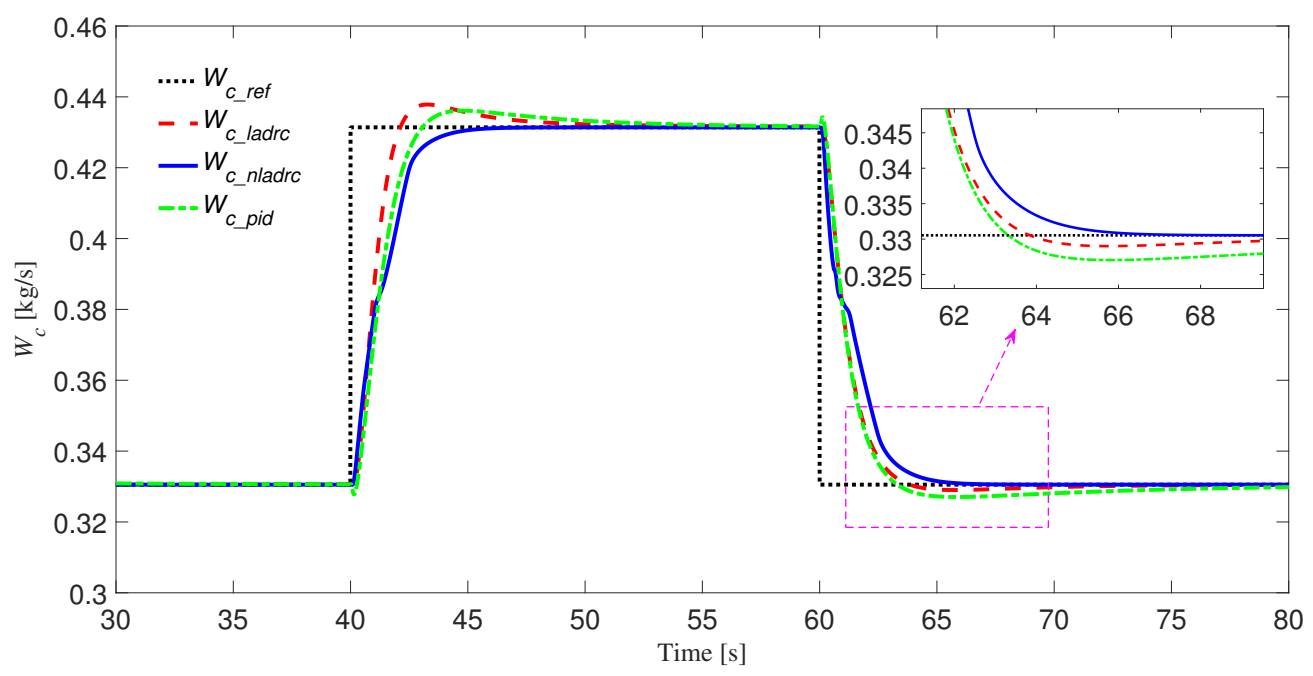

Figure 5. Response curve of mass air flow $W_{c}$.

Compare the tracking effect of intake manifold pressure $p_{i m}$ in Figure 4, or the tracking effect of mass air flow $W_{c}$ in Figure 5. Obviously, system with NLADRC controller tracks square wave signals better. In the figure, the NLADRC controller tracks the desired intake manifold pressure $p_{i m_{-} r e f}$ or mass air flow $W_{c_{-} r e f}$ without overshoot, while the LADRC controller and PID controller have relatively large overshoot. The intake manifold pressure $p_{i m}$ and mass air flow $W_{c}$ of diesel engines are the outputs of dynamic system, which have certain inertia and cannot change suddenly. However, the set values $p_{\text {im_ref }}$ and $W_{c_{-} r e f}$ are given outside the system and can be changed instantaneously. If we use their deviation to produce control effect directly, it will lead to the initial error is too large, and the controller will have a great control effect, which will have a great impact on the system and easy to produce overshoot. TD was mentioned earlier when we introduced the structure of the NLADRC controller designed for the $p_{i m}$ loop. In the $p_{i m}$ loop, TD converts transient intake manifold pressure $p_{i m_{-} d}$ into a slow-varying transition process signal $p_{i m_{-} v 1}$. In this way, the slowly changing transition process signal $p_{i m_{-} v 1}$ minus the output signal $p_{i m}$ of diesel engines will not produce excessive deviation, and NLADRC controller will not produce excessive control effect, so that the intake manifold pressure $p_{i m}$ of the diesel engine does not generate overshoot. In the previous NLESO design, we introduced the nonlinear function $f a l(e, \alpha, \delta)$, whose image is shown in Figure 6. When the parameter $\alpha$ of the nonlinear function is equal to 1 , it becomes a linear form of the error. As can be seen from the figure, the linear form and the nonlinear form intersect at $(1,1)$. When the error is greater than 1 , the value of the nonlinear function is less than that of the linear form, so the control effect generated by the NLADRC controller is less than that of the linear form, so the system response with the NLADRC controller will not produce overshot.

In addition, the setting time of NLADRC controller is about $6 \mathrm{~s}$, while that of LADRC controller and PID controller is 2 times and 3 times of that of NLADRC controller, respectively. 


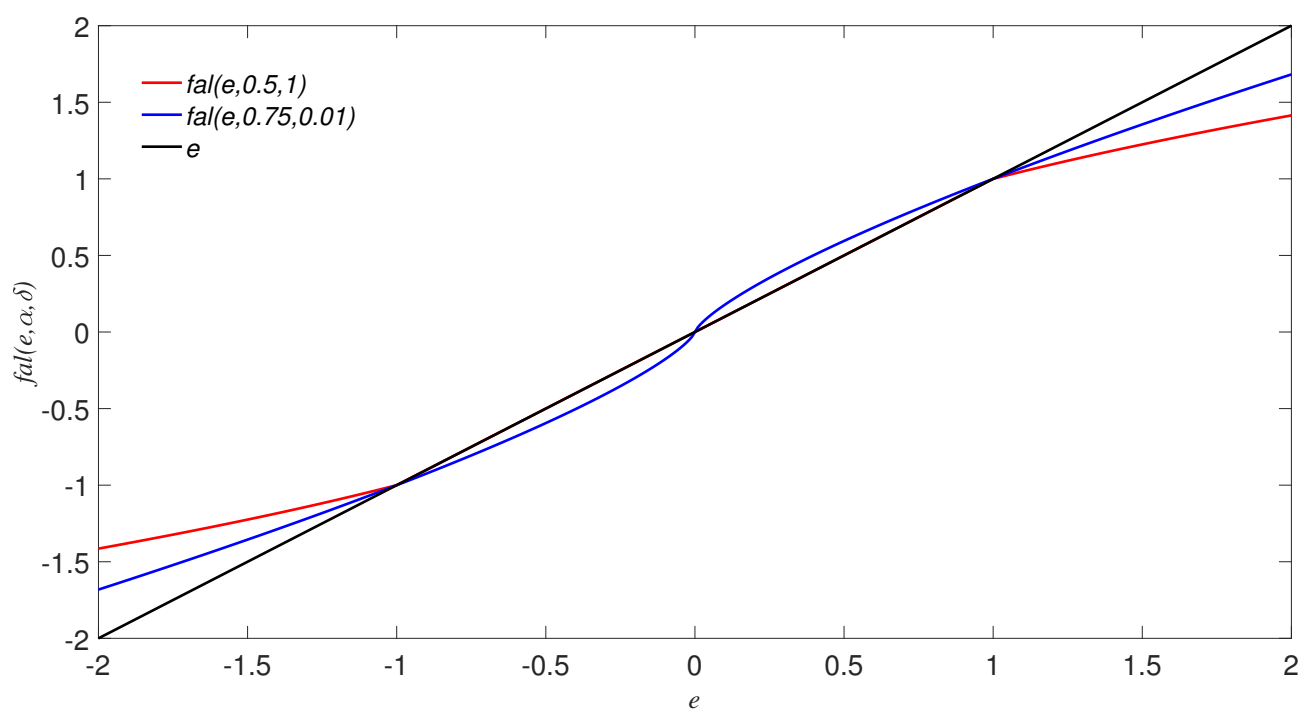

Figure 6. The nonlinear function $f a l(e, \alpha, \delta)$ and the linear function $e$.

\subsection{Disturbance Rejection}

In the previous section, we compared the effect of three controllers on tracking square wave signals. In this part, we will verify the resistance of the three controllers to control disturbances. The control disturbance is $d$ in the NLADRC controller structure described in Section 3. In this part, we take the $p_{i m}$ loop as an example to compare the resistance of the three controllers to external control disturbances. At $40 \mathrm{~s}$, we set the desired intake manifold pressure, and over time the diesel engine's intake manifold pressure reaches the desired value. In addition, then at $60 \mathrm{~s}$, we add a square wave control interference with an amplitude of 10 and a width of $10 \mathrm{~s}$. Figure 7 shows the resistance of the three controllers to square wave disturbances. It is obvious that the response curve of the NLADRC controller has a slight amplitude change after adding the disturbance, and quickly returns to the expected value after $2 \mathrm{~s}$. However, the amplitude variation of the LADRC controller and PID controller is much larger than that of the NLADRC controller, and the recovery time is relatively long. Next, we analyze why NLADRC controller is better than LADRC controller and PID controller in resisting square wave disturbance. First, let us look at the first figure in Figure 8, which shows the output signals $u_{c}$ of the three controllers. The NLESO in NLADRC controller accurately estimates the amplitude and period of the square wave form disturbance and compensates to the control effect $u_{c}$. We can also see from the image of $u_{c}$ that at $60 \mathrm{~s}$ the compensated disturbance in the NLADRC controller is closer to the added control disturbance. The output signal $u_{c}$ of the controller plus the external control disturbance $d$ is the input signal $u_{v g t}$ of the diesel engine, which is shown in the second figure of Figure 8 . As can be seen from the figure, the $u_{\text {vgt_nladrc }}$ is basically unchanged after disturbance is added. This is because the compensated disturbance in $u_{c}$ and the external disturbance $d$ cancel each other. Therefore, compared with LADRC controller and PID controller, NLADRC controller can resist external interference better.

In addition to square wave form disturbance, sinusoidal form control disturbances is also considered to be added. Sinusoidal interference with an amplitude of 5 and a period of $20 \mathrm{~s}$ was added at $60 \mathrm{~s}$, and Figures 9 and 10 present the resistance effect of the three controllers against sinusoidal disturbance. For sinusoidal control interference, we have the same conclusion as the square wave form, which will not be repeated here. 


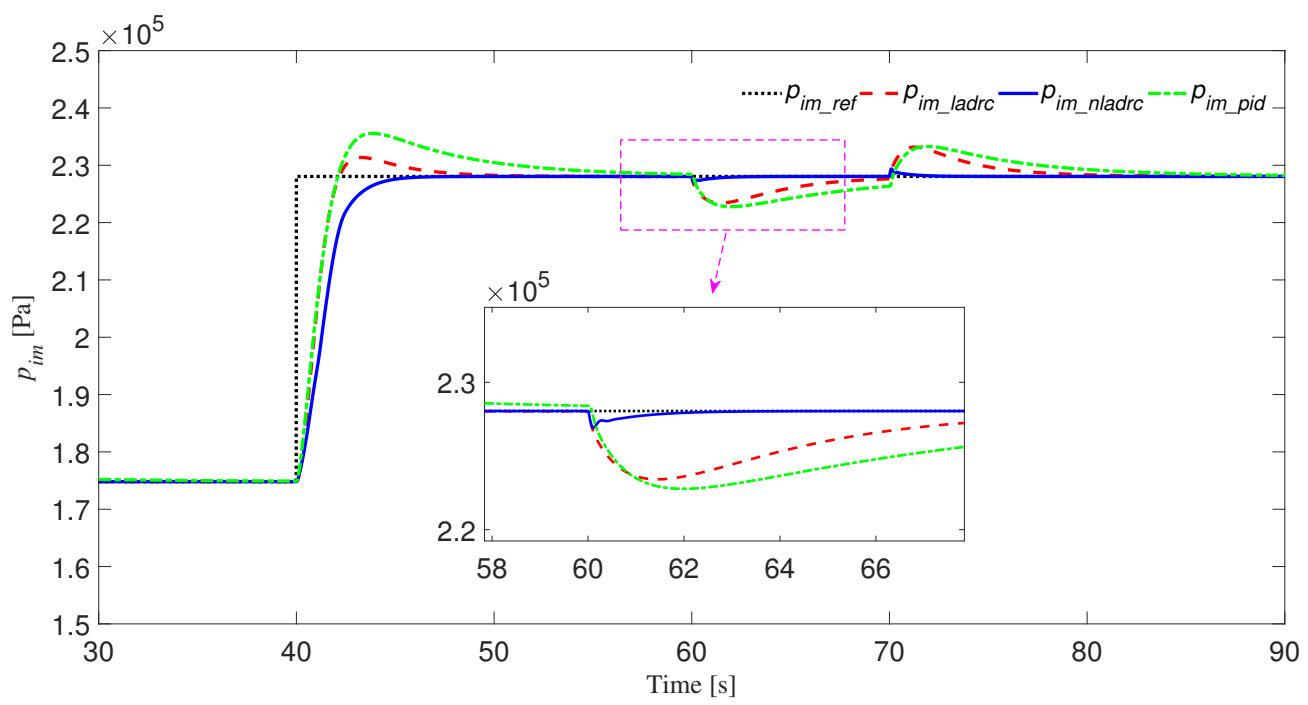

Figure 7. Response curve of intake manifold pressure $p_{i m}$ after adding square wave form control disturbance.
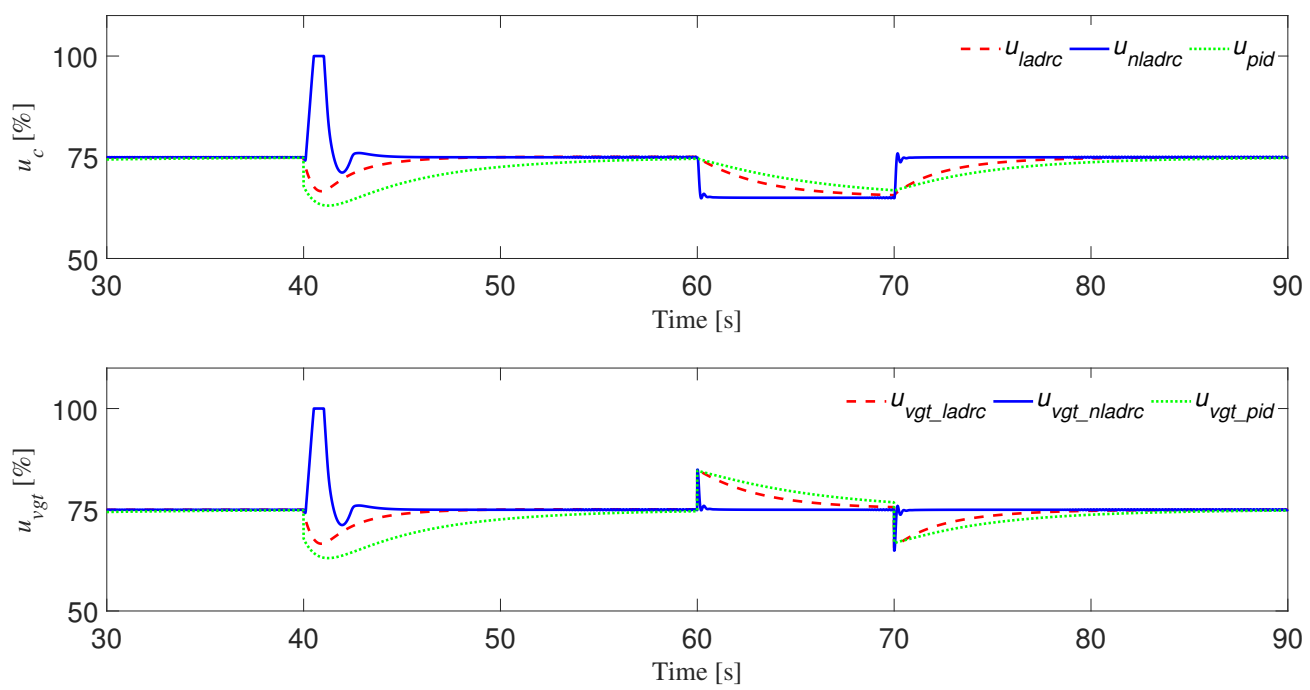

Figure 8. Output signal $u_{c}$ of controller and input signal $u_{v g t}$ of VGT valve.

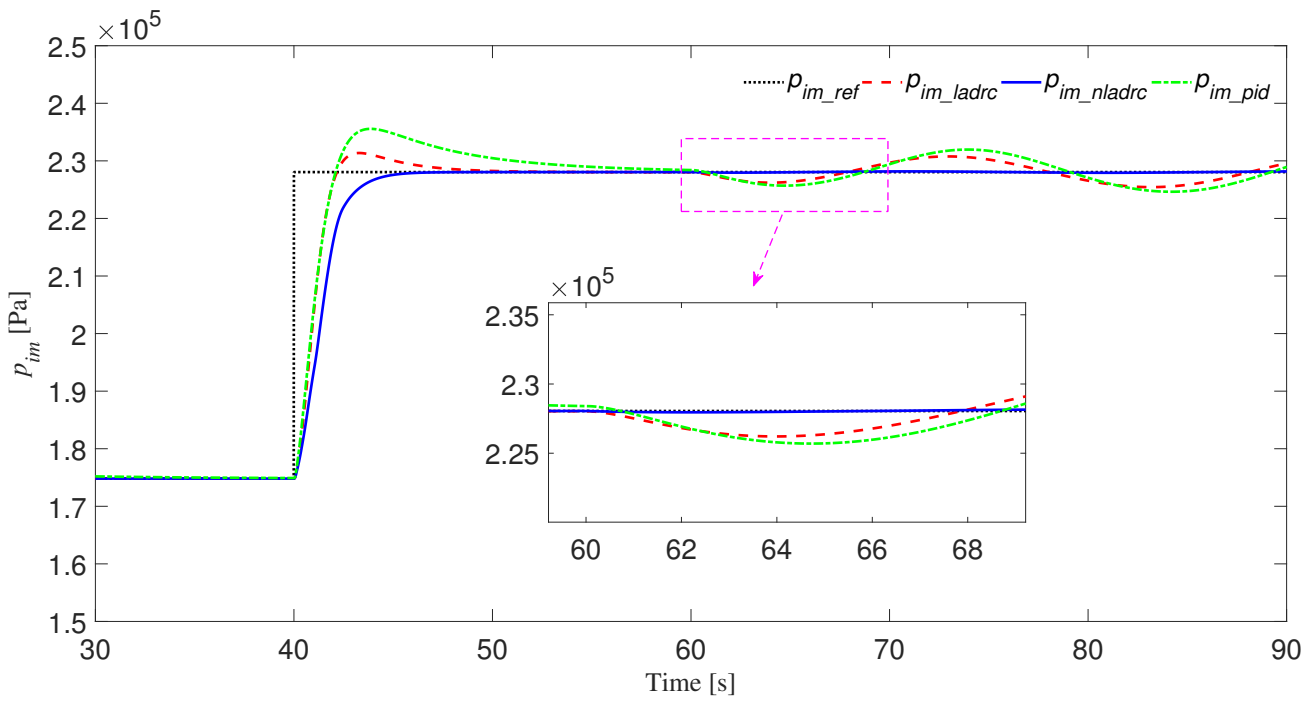

Figure 9. Response curve of intake manifold pressure $p_{i m}$ after adding sinusoidal control disturbance. 

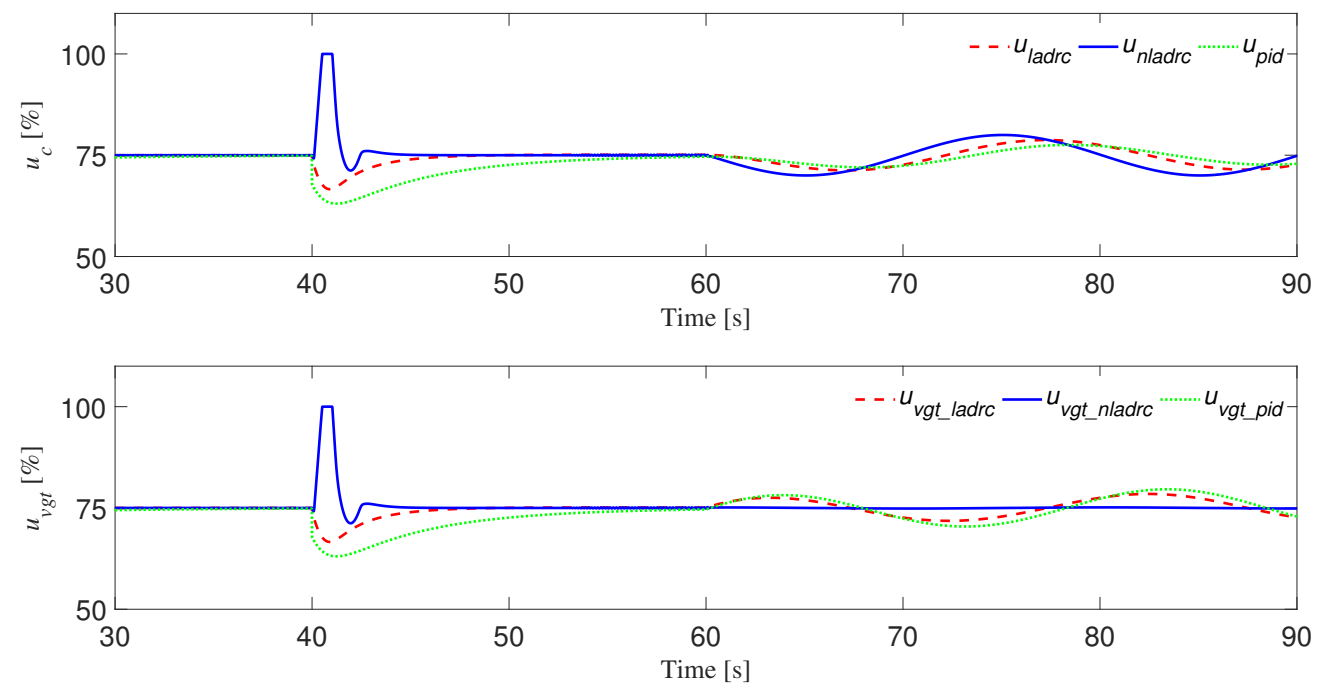

Figure 10. Output signal $u_{c}$ of controller and input signal $u_{v g t}$ of VGT valve.

\subsection{Robustness}

Because the diesel engine needs to change the working condition frequently, the controller designed must be able to have strong robust performance to the changing working condition. In this part, we mainly verify whether the NLADRC controller has strong robust performance to the change of working conditions from the two aspects of speed $n_{e}$ and fuel injection $u_{\delta}$. First, we verify that the controller is robust to changes in speed. Before $80 \mathrm{~s}$, the speed $n_{e}$ of diesel engines is $1900 \mathrm{r} / \mathrm{min}$. The engine speed is reduced to $1700 \mathrm{r} / \mathrm{min}$ and $1500 \mathrm{r} / \mathrm{min}$ at the time of $80 \mathrm{~s}$ and $140 \mathrm{~s}$, respectively. Figures 11 and 12 respectively show the response curves of intake manifold pressure $p_{i m}$ and mass air flow $W_{c}$ before and after changing the speed. In addition, the fuel injection $u_{\delta}$ of the engine is increased from $50 \mathrm{mg} /$ cycle to $200 \mathrm{mg} /$ cycle with steps of $50 \mathrm{mg} / \mathrm{cycle}$, and the simulation images are obtained without adjusting the control parameters, as shown in Figures 13 and 14. In the $p_{i m}$ loop and the $W_{c}$ loop, the NLADRC controller can track the given signal faster and better without recalibrating parameters after changing the engine speed and fuel injection. Therefore, the NLADRC controller has strong robustness to the change of diesel engine operating conditions.

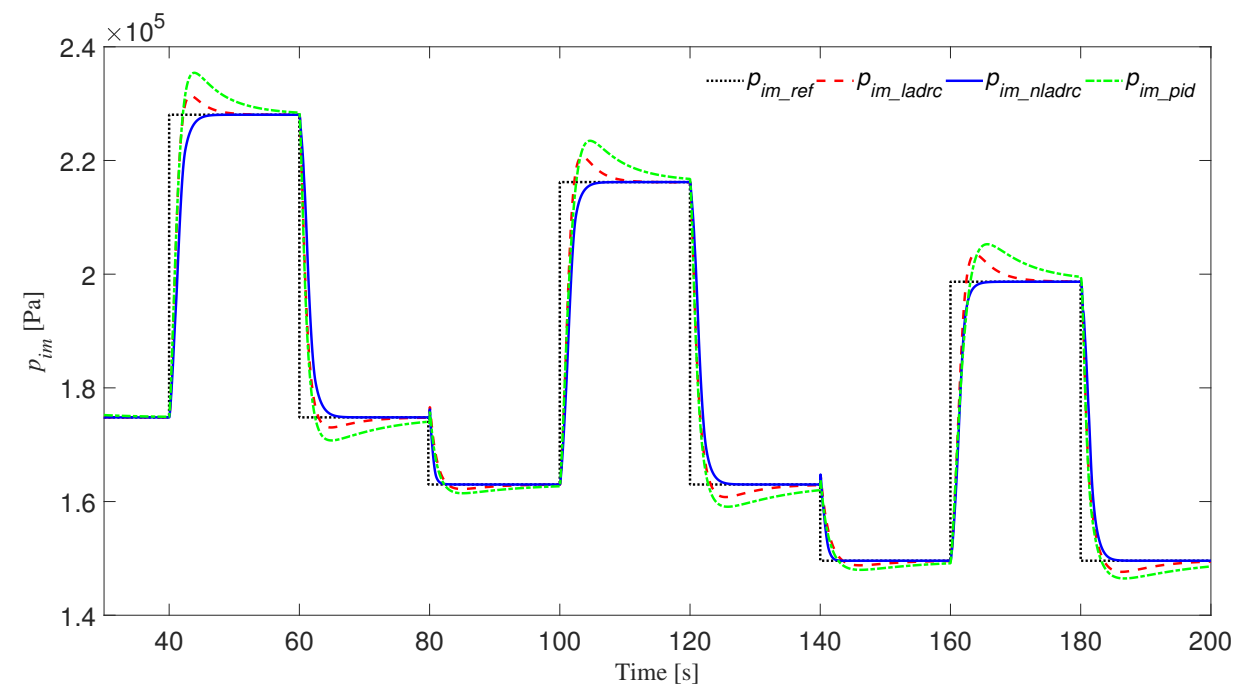

Figure 11. The response curve of intake manifold pressure at different engine speeds.

Although NLADRC controller has good tracking performance, resistance to external interference and robust performance to the change of working conditions for VGT-EGR system in diesel engines, 
too many parameters of NLADRC controller are too troublesome to adjust, which may limit the wide application of NLADRC controller.

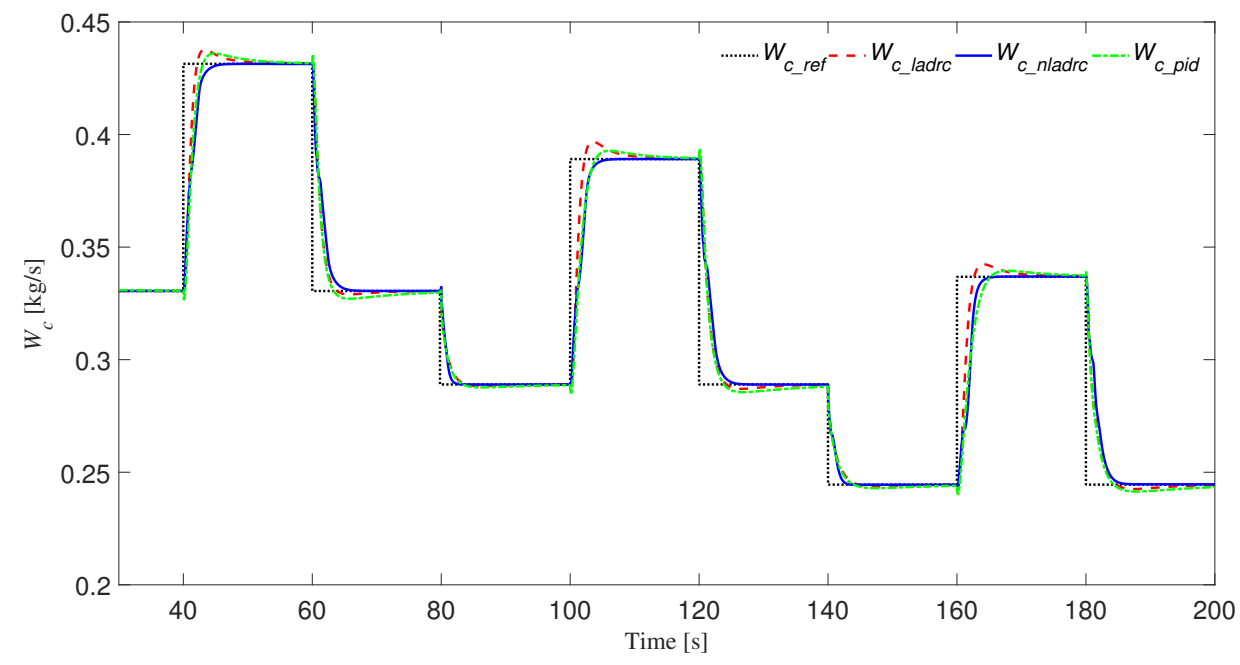

Figure 12. The response curve of mass air flow at different engine speeds.

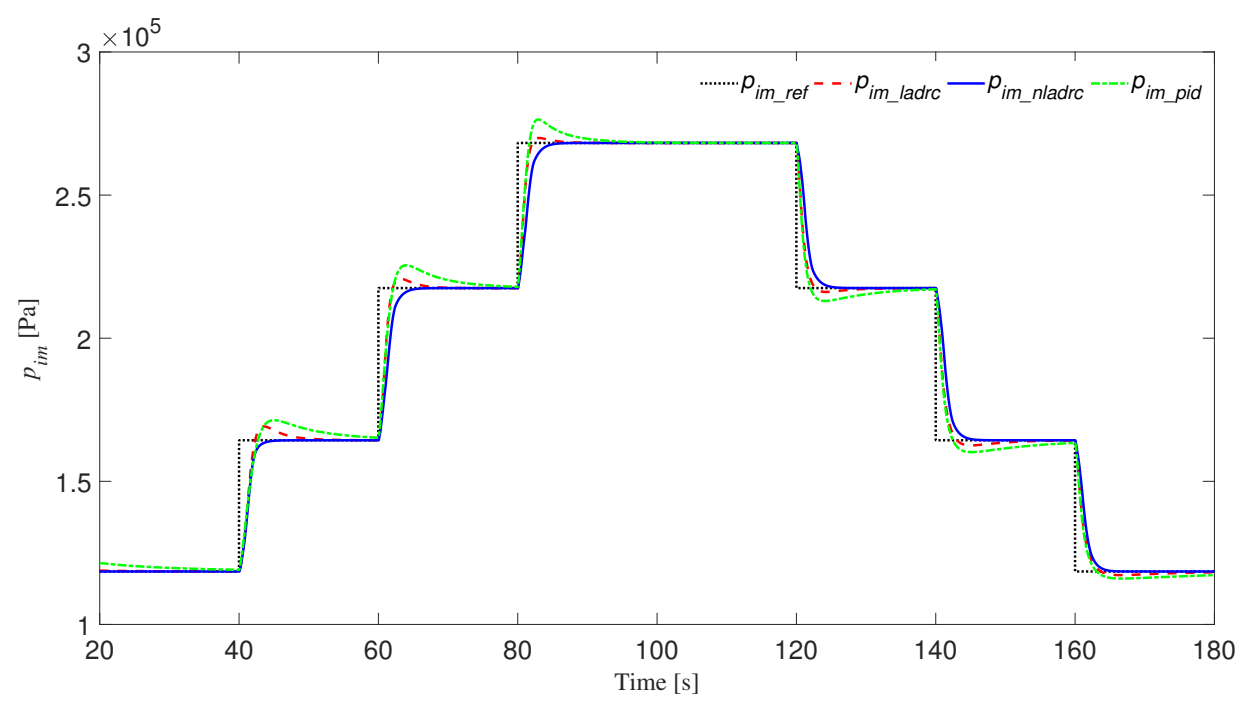

Figure 13. The response curve of intake manifold pressure under different fuel injection conditions.

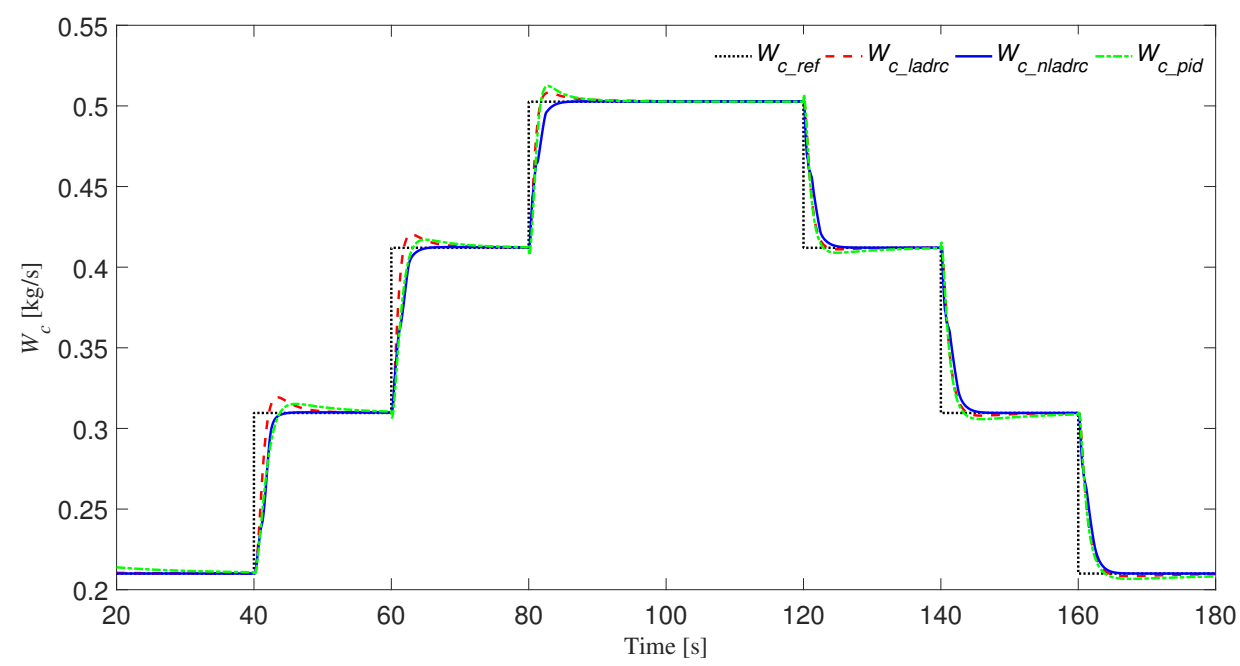

Figure 14. The response curve of mass air flow under different fuel injection conditions. 


\section{Conclusions}

In this paper, considering that the VGT-EGR system of diesel engines is a complex nonlinear system with unknown dynamics, the operating conditions of the system often change in actual operation. Therefore, the control strategy of intake manifold pressure and mass air flow of diesel engines based on NLADRC control theory is proposed. To ensure the rationality of the designed controller, the convergence proof of the designed NLESO is also given. Finally, the performance of the designed NLADRC controller is verified from the following three aspects: the tracking effect of the set signal, the resistance to external disturbance and the robust performance to the change of fuel injection and speed. Compared with the LADRC controller and PID controller, the designed NLADRC controller is effective for the VGT-EGR system in diesel engines.

Author Contributions: Conceptualization, Y.W. and Y.L.; methodology, Y.W.; software, P.Z. and J.Z.; validation, P.Z. and J.Z.; resources, P.Z., J.Z., Y.W. and Y.L.; writing-original draft preparation, P.Z., J.Z., Y.W. and Y.L.; writing-review and editing, P.Z., J.Z., Y.W. and Y.L.; project administration, Y.W. and Y.L.; funding acquisition, Y.W., Y.L. and Y.W. All authors have read and agreed to the published version of the manuscript.

Funding: This research was funded by the National Natural Science Foundation of China under Grant 61773090, Liao Ning Revitalization Talents Program under Grant XLYC1907100, XLYC1907070, and in part by the Fundamental Research Funds for the Central Universities under Grant DUT19LAB37.

Conflicts of Interest: The authors declare no conflict of interest.

\section{Nomenclature}

$\begin{array}{ll}\text { VGT } & \text { variable geometry turbine } \\ \text { EGR } & \text { exhaust gas recirculation } \\ \text { MIMO } & \text { multi-input multi-output } \\ \text { DIDO } & \text { double-input double-output } \\ \text { SISO } & \text { single-input single-output } \\ \text { PID } & \text { proportional-integral-derivative } \\ \text { MPC } & \text { model predictive control } \\ \text { CLF } & \text { control Lyapunov function } \\ \text { ADRC } & \text { Active disturbance rejection control } \\ \text { ESO } & \text { extended state observer } \\ \text { LADRC } & \text { linear active disturbance rejection control } \\ \text { NLADRC } & \text { nonlinear active disturbance rejection control } \\ \text { TD } & \text { tracking differentiator } \\ \text { NLESO } & \text { nonlinear extended state observer } \\ \text { NLSEF } & \text { nonlinear states error feedback control laws } \\ p_{i m} & \text { intake manifold pressure }[\mathrm{Pa}] \\ p_{e m} & \text { exhaust manifold pressure }[\mathrm{Pa}] \\ T_{i m} & \text { intake manifold temperature }[\mathrm{K}] \\ T_{e m} & \text { exhaust manifold temperature }[\mathrm{K}] \\ V_{i m} & \text { intake manifold volume }\left[\mathrm{m}^{3}\right] \\ V_{e m} & \text { exhaust manifold volume }\left[\mathrm{m}^{3}\right] \\ p_{a m b} & \text { ambient pressure }[\text { Pa] } \\ T_{a m b} & \text { ambient temperature }[\mathrm{K}] \\ P_{c} & \text { compressor power }[\mathrm{W}] \\ P_{t} & \text { turbine power }[\mathrm{W}] \\ u_{v g t} & \text { VGT valve opening ratio }[\%] \\ u_{e g r} & \text { EGR valve opening ratio [\%] } \\ W_{c} & \text { mass air flow }[\mathrm{kg} / \mathrm{s}] \\ W_{f} & \text { fuel mass flow }[\mathrm{kg} / \mathrm{s}] \\ W_{e g r} & \text { EGR gas mass flow }[\mathrm{kg} / \mathrm{s}] \\ W_{t} & \text { exhaust gas mass }[\mathrm{kg} / \mathrm{s}] \\ W_{e} & \text { mass flow into the cylinder }[\mathrm{kg} / \mathrm{s}] \\ & \end{array}$


$R \quad$ gas constant [J/ $\mathrm{kgK}]$

$\eta_{m} \quad$ turbocharger mechanical efficiency

$c_{p} \quad$ constant pressure specific heat capacity [J/kgK]

$\eta_{c} \quad$ compressor isentropic efficiency

$\eta_{t} \quad$ turbine isentropic efficiency

$A_{e g r}$ effective cross-sectional areas of the EGR valve $\left[\mathrm{m}^{2}\right]$

$A_{v g t}$ effective cross-sectional areas of the VGT valve $\left[\mathrm{m}^{2}\right]$

\section{References}

1. Wahlström, J.; Eriksson, L. Modelling diesel engines with a variable-geometry turbocharger and exhaust gas recirculation by optimization of model parameters for capturing non-linear system dynamics. Proc. Inst. Mech. Eng. Part D J. Automob. Eng. 2011, 225, 960-986. [CrossRef]

2. Kolmanovsky, I.; Morall, P.; Van Nieuwstadt, M. Issues in modelling and control of intake flow in variable geometry turbocharged. In Systems Modelling and Optimization, Proceedings of the 18th IFIP TC7 Conference; CRC Press: Boca Raton, FL, USA,1999, Volume 396, p. 436.

3. Shen, T.; Kang, M.; Gao, J.; Zhang, J.; Wu, Y. Challenges and solutions in automotive powertrain systems. J. Control. Decis. 2018, 5, 61-93. [CrossRef]

4. Wahlström, J.; Eriksson, L.; Nielsen, L.; Pettersson, M. PID controllers and their tuning for EGR and VGT control in diesel engines. In Preprints of the 16th IFAC World Congress; Elsevier: Prague, Czech Republic, 2005.

5. Wahlström, J.; Eriksson, L. Non-Linear Compensator for Handling Non-Linear Effects in EGR VGT Diesel Engines; Linköping University Electronic Press: Linköping, Sweden, 2009.

6. Khan, M.K.; Goh, K.B.; Spurgeon, S.K. Second order sliding mode control of a diesel engine. Asian J. Control. 2003, 5, 614-619. [CrossRef]

7. Ali, S.A.; N'doye, B.; Nicolas, L. Sliding mode control for turbocharged diesel engine. In Proceedings of the IEEE 2012 20th Mediterranean Conference on Control \& Automation (MED), Barcelona, Spain, 3-6 July 2012; pp. 996-1001.

8. Murilo, A.; Alamir, M.; Ortner, P. Multivariable control strategy based on a parameterized NMPC for a diesel engine air path. In Proceedings of the 21st International Congress of Mechanical Engineering, Natal, Brazil, 24-28 October 2011.

9. Ortner, P.; Del Re, L. Predictive control of a diesel engine air path. IEEE Trans. Control. Syst. Technol. 2007, 15, 449-456. [CrossRef]

10. Kuzmych, O.; Aitouche, A. CLF-based nonlinear control design for turbocharged diesel engine. In Proceedings of the IEEE 21st Mediterranean Conference on Control and Automation, Chania, Greece, 25-28 June 2013; pp. 1484-1489.

11. Jankovic, M.; Kolmanovsky, I. Robust nonlinear controller for turbocharged diesel engines. In Proceedings of the 1998 American Control Conference, ACC (IEEE Cat. No. 98CH36207), Philadelphia, PA, USA, 26 June 1998; Volume 3, pp. 1389-1394. doi:10.1109/ACC.1998.707047. [CrossRef]

12. Wu, Y.; Shen, T. Policy Iteration Approach to Control Residual Gas Fraction in IC Engines Under the Framework of Stochastic Logical Dynamics. IEEE Trans. Control. Syst. Technol. 2017, 25, 1100-1107. [CrossRef]

13. Shen, $\mathrm{X} . ; \mathrm{Wu}, \mathrm{Y} . ;$ Shen, T. Logical control scheme with real-time statistical learning for residual gas fraction in IC engines. Sci. China Inf. Sci. 2018, 61, 010203. [CrossRef]

14. Zhang, J.; Wu, Y. A stochastic logical model-based approximate solution for energy management problem of HEVs. Sci. China Inf. Sci. 2018, 61, 70207. [CrossRef]

15. Shen, X.; Zhang, Y.; Sata, K.; Shen, T. Gaussian Mixture Model Clustering-based Knock Threshold Learning in Automotive Engines. IEEE/ASME Trans. Mechatron. 2020. [CrossRef]

16. Shen, X.; Zhang, Y.; Shen, T.; Khajorntraidet, C. Spark advance self-optimization with knock probability threshold for lean-burn operation mode of SI engine. Energy 2017, 122, 1-10. [CrossRef]

17. Gao, J.; Zhang, Y.; Zhang, J.; Shen, T. Adaptive Internal Model Based Control of the RGF Using Online Map Learning and Statistical Feedback Law. IEEE/ASME Trans. Mechatron. 2019, 25, 1117-1128. [CrossRef]

18. Liu, N.; Qin, S. A novel neurodynamic approach to constrained complex-variable pseudoconvex optimization. IEEE Trans. Cybern. 2018, 49, 3946-3956. [CrossRef] [PubMed] 
19. Hu, J.; Zhang, H.; Yu, X.; Liu, H.; Chen, D. Design of sliding-mode-based control for nonlinear systems with mixed-delays and packet losses under uncertain missing probability. IEEE Trans. Syst. Man Cybern. Syst. 2019. [CrossRef]

20. Han, J. From PID to active disturbance rejection control. IEEE Trans. Ind. Electron. 2009, 56, 900-906. [CrossRef]

21. Yang, L.; Zhang, W.; Huang, D. Robust trajectory tracking for quadrotor aircraft based on ADRC attitude decoupling control. J. Beijing Univ. Aeronaut. Astronaut. 2015, 41, 1026-1033.

22. Wang, J.; Ma, H.; Cai, W.; Shui, H.; Nie, B. Research on micro quadrotor control based on ADRC. J. Proj. Rocket. Missiles Guid. 2008, 28, 31-40.

23. Zhang, H.B.; Wang, R.X.; Lin, Y.H.; Li, Y.J. Active Disturbance Rejection Decoupling Control for Aero-Engines. In Advanced Materials Research; Trans Tech Publ.: Stafa, Switzerland, 2012; Volume 383, pp. 7702-7707.

24. Song, K.; Xie, H.; Yang, S.; Zhang, H.; Zheng, Q.; Tatsumi, J.; Gao, Z. Dynamic feed-forward control aided with active disturbance rejection for boost pressure and mass air flow control of diesel engines. In Proceedings of the IEEE 33rd Chinese Control Conference, Nanjing, China, 28-30 July 2014; pp. 239-244.

25. Xie, H.; Song, K.; Yang, S.; Tatsumi, J.; Zheng, Q.; Zhang, H.; Gao, Z. On decoupling control of the VGT-EGR system in diesel engines: A new framework. IEEE Trans. Control. Syst. Technol. 2015, 24, 1788-1796. [CrossRef]

26. Yang, S.; Xie, H.; Song, K.; Li, X.; Gao, Z. On boost pressure control of diesel engines with double-layer passage turbocharger. In Proceedings of the IEEE 2015 54th Annual Conference of the Society of Instrument and Control Engineers of Japan (SICE), Hangzhou, China, 28-30 July 2015; pp. 1276-1282.

27. Wang, J.; Wang, X.; Luo, Z.; Assadian, F. Active Disturbance Rejection Control of Differential Drive Assist Steering for Electric Vehicles. Energies 2020, 13, 2647. [CrossRef]

28. Shi, G.; Wu, Z.; Guo, J.; Li, D.; Ding, Y. Superheated Steam Temperature Control Based on a Hybrid Active Disturbance Rejection Control. Energies 2020, 13, 1757. [CrossRef]

29. Zhou, K.; Ai, M.; Sun, Y.; Wu, X.; Li, R. PMSM Vector Control Strategy Based on Active Disturbance Rejection Controller. Energies 2019, 12, 3827. [CrossRef]

30. Guo, B.; Zhao, Z. On the convergence of an extended state observer for nonlinear systems with uncertainty. Syst. Control. Lett. 2011, 60, 420-430. [CrossRef]

(C) 2020 by the authors. Licensee MDPI, Basel, Switzerland. This article is an open access article distributed under the terms and conditions of the Creative Commons Attribution (CC BY) license (http://creativecommons.org/licenses/by/4.0/). 